\title{
ERRATUM
}

“CAN CAP GUIDELINE ADHERENCE IMPROVE PATIENT OUTCOME IN INTERNAL MEDICINE DEPARTMENTS?”. F. BLASI, I. IORI, A. BULFONI, S. CORRAO, S. COSTANTINO AND D. LEGNANI. EUR RESPIR J 2008 ; $32: 902-910$.

Unfortunately, the therapy information presented on the left-hand side of figure 3 was incomplete; this specifically concerned the therapy name appearing on the lower left of the figure. Figure 3 should have appeared as follows:

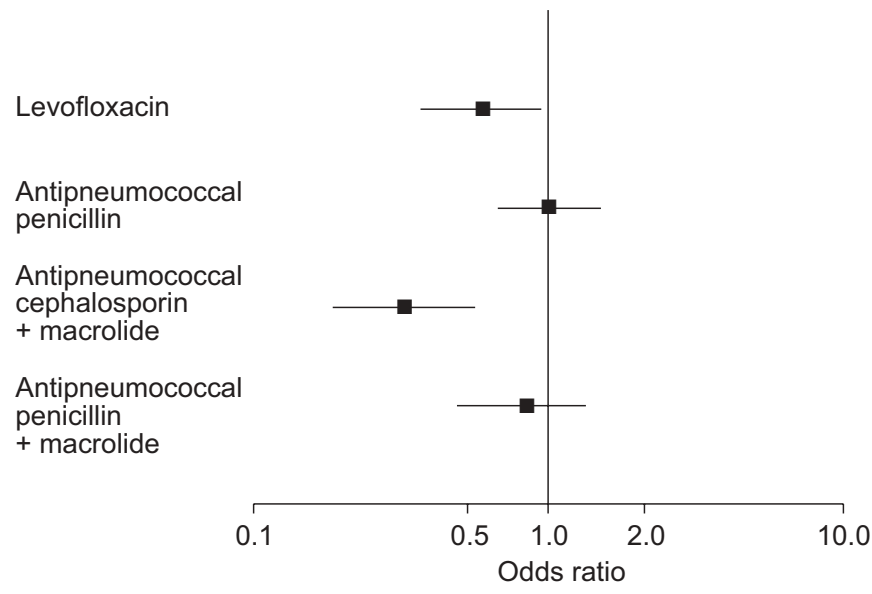

FIGURE 3. Mortality during first therapy cycle according to main initial therapies. Data are presented as adjusted odds ratios (ORs) with 95\% confidence intervals (Cls) versus antipneumococcal cephalosporin alone. Multiple logistic regression model including initial therapy, study phase, Fine score (as a numerical variable on a 10-point scale) and previous antibiotic treatment (yes or no). ORs (95\% Cls) were as follows: levofloxacin 0.59 (0.37-0.94), $p=0.026$; antipneumococcal penicillin $1.01(0.68-1.50), p=0.97$; antipneumococcal cephalosporin and macrolide 0.32 (0.19-0.56), $\mathrm{p}<0.001$; antipneumococcal penicillin and macrolide 0.81 (0.50-1.34), $p=0.42$. Mortality rates: antipneumococcal cephalosporin, $16.2 \%$; levofloxacin, 9.1\%; antipneumococcal penicillin, 15.9\%; antipneumococcal cephalosporin and macrolide, 5.7\%; antipneumococcal penicillin and macrolide, $12.2 \%$.

\section{AUTHOR CORRECTIONS}

“THE SECRET LIFE OF STEROIDS IN ASTHMA". P.J. STERK, C.Y. YICK AND A.M. SLATS. EUR RESPIR J 2008; 32: $1135-1137$.

Unfortunately, the misrepresentative term "inhibition" was used in the penultimate paragraph of the above manuscript. The sixth sentence of this section should have read as follows: "The responsible signalling pathways are not fully understood, and could not only be related to transcriptional and post-transcriptional regulation of MKP-1 and calcium-mobilising second messengers [26], but also to altered transcription of proteins that are responsible for airway smooth muscle phenotype, including contractile elements, cytoskeleton, cell surface molecules, and cytokines or mediators with autocrine function [23, 27]." The authors apologise for this error. 